TITLE:

\author{
PRINCIPAL INVESTIGATOR: Herbert F. Wang \\ Department of Geology and Geophysics \\ University of Wisconsin-Madison \\ Madison, WI 53706 \\ Telephone: (608) 262-5932 \\ FAX: (608) 262-0693 \\ SUBMITTED TO: \\ Dr. William C. Luth, ER-15 \\ Department of Energy \\ Division of Engineering and Geosciences \\ Office of Basic Energy Sciences \\ Washington, D. C. 20545 \\ FGO2-91ER, 1194
}

\title{
DISCLAIMER
}

March 1992

\begin{abstract}
This report was prepared as an account of work sponsored by an agency of the United States Government. Neither the United States Government nor any agency thereof, nor any of their employees, makes any warranty, express or implied, or assumes any legal liability or responsibility for the accuracy, completeness, or usefulness of any iliformation, apparatus, product, or process disclosed, or represents that its use would not infringe privately owned rights. Reference herein to any specific commercial product, process, or service by trade name, trademark, manufacturer, or otherwise does not necessarily constitute or imply its endorsement, recommendation, or favoring by the United States Government or any agency thereof. The views and opinions of authors expressed herein do not necessarily state or reflect those of the United States Government or any agency thereof.
\end{abstract}




\section{SCOPE OF PROJECT}

The research program is an experimental study of static and dynamic poroelastic behavior of rocks. Measurements of Skempton's cocfficient and undrained Poisson's ratio together with drained bulk modulus and shear modulus will provide a complete set of the four poroelastic moduli that appear in Biot's (1941) constitutive relations. Stress coupling to fluid flow in fractured rock can occur also through changes of fracture permeability due to fracture compressibility. Numerical models that include this effect will be compared with standard double porosity models of fluid extraction from oil reservoirs. Wave velocity and attenuation measurements will be made from seismic to ultrasonic frequencies to establish a phenomenological model of the effects of permeability, porosity and saturation for seismic exploration of oil and gas and for seismic characterization of an aquifer for environmental restoration and waste remediation.

\section{SUMMARY OF PROGRESS}

\section{Hydraulic Diffusivity by Periodic Loading}

A new technique has been developed for measuring hydraulic diffusivities in sandstones that have permeability in the millidarcy range. It is based on using a semiconductor strain gage incorporated into an end plug used previously for measuring Skempton's coefficient (Green and Wang, 1986). A servocontrolled pressure system is used to generate a cyclic pore pressure variation with periods between one and twenty seconds (Roeloffs et al., 1979). After a few cycles the periodic steady state solution of this boundary value problem (Carslaw and Jaeger, p. 105, 1959) can be fitted for the hydraulic diffusivity from either the phase shift or amplitude of the pressure signal recorded in the no-flow end plug. The hydraulic diffusivities obtained for Berea sandstone is about $0.4 \times 10^{-3} \mathrm{~m}^{2} / \mathrm{s}$.

In order to measure both permeability $K$ and hydraulic diffusivity, $\kappa=K / \mu S_{s}$, where $S_{s}$ is specific storage and $\mu$ is viscosity, pressure can be measured in a fixed volume fluid reservoirs 
at the inlet or outlet side of the sample (Brace et al., 1968; Zoback and Byerlee, 1975; Trimmer, 1982). We are presently installing apparatus constructed by Haimson and Lee at the University of Wisconsin, based on Zoback and Byerlee's method. The end pistons in the Hair.son and Lee apparatus will exert a vertical load equal to the applied pore pressure. Incorporating this stress boundary condition in the Biot theory will eliminate consideration of specific storage in the sample, and hence yield permeability independently of storage.

\section{Double Porosity Modeling}

Reservoir engineess have treated a fractured medium as having dual porosity and permeability (Walten and Root, 1963). The diffusion equation, which is written for fracture pressure, includes a matrix-to-fracture source term that is proportional to the local pressure difference. Boulton and Streitsova (1977) have solved the problem of constant rate withdrawal from a well in a reservoir with uniformly spaced horizontal fractures. In cooperation with John Nitao at Lawrence Livermore National Laboratory, we have derived a set of governing equations for the situation in which pressure lowering in the fracture will produce significant reduction in fracture permeability through increased effective vertical stress. The fractional change in fracture aperture is approximately equal to the fractional change in fracture pressure (Walsh and Grosenbaugh, 1978). Therefore, reducing the fracture pressure by a factor of two will reduce fracture permeability by a factor of eight, according to the cubic law relating fracture permeability to fracture aperture. We will couple the fracture compressibility model of Walsh and Grosenbaugh (1978) to the hydraulic model of Boulton and Streltsova.

\section{Double Medium Diffusion}

The concept of a double porosity medium used for fluid flow in fractured rock has been applied to diffusion in rock containing a small, continuous fluid phase that tessellates the rock matrix. The double medium model consists of overlapping continua in which two 
concentration values --one in the fluid and one in the solid -- are associated with each point in the problem domain. One equation is the diffusion equation for the fluid concentration, including a source term for transport from the solid matrix to the fluid. This solid-to-fluid flux is proportional to the difference between the concentration in the solid and the concentration in the fluid times the solid-fluid partition coefficient. The proportionality constant is the producl of the solid diffusivity and a geometric factor associated with the surface area of the solid element. The second coupled equation equates this flux to the change in concentration in the solid element.

The model was applied to laboratory iron diffusion data in olivine by Watson (1991) and to fielu Jxygen isotope data at marble-metagranite contacts by Cartwright and Valley (1991). In both examples, concentration profiles are calculated for a diffusion process taking place at constant temperature, in which a boundary value changes suddenly and is held constant subsequently. The model gives insight into the relative role of diffusion in the fluid and solid phases of the rock. The fluid is the fast diffusion path, but the solid contains the volumetrically significant amount of the diffusing species. For the specified boundary, the matrix concentration decays exponentially with time, with the decay constant controlled by the solid diffusivity. The concentration profile away from the boundary is also approximately exponential, with the decay distance controlled by the ratio of the fluid to solid diffusivities. 


\section{REFERENCES}

Berryman, J. G., Effective stress for transport properties of inhomogeneous porous rock, J. Geophys. Res., 1992, submitted for publication.

Biot, M. A., General theory of three-dimensional consolidation, J. Appl. Phys., 12, 155-164, 1941.

Biot, M. A., Theory of propagation of elastic waves in a fluid-saturated porous solid. I. Low-frequency range, J. Acous. Soc. Am., 28, 168-178, 1056a.

Biot, M. A., Theory of propagation of elastic waves in a fluid saturated porous solid II. Higher frequency range, J. Acous. Soc. Am., 28, 179-191, $1956 \mathrm{~b}$.

Boulton, N. S., and T. D. Streltsova, Unsteady flow to a pumped well in a fissured water-bearing formation, J. Hydrology, 35, 257-2.69, 1977.

Brace, W. F., J. B. Walsh, and W. T. Frangos, Permeability of granite under high pressure, J. Geophys. Res., 73, 2225-2236, 1968. 
Carslaw, H. S., and J. C. Jacger, Conduction of Heat in Solids, 510pp., Oxford, 1959.

Cartwright, I., and J. W. Valley, Steep oxygen-isotope gradients at marble-metagranite contacts in the northwest Adirondack Mountains, New York, USA: products of fluid-hosted diffusion, Earth and Planet. Sci. Letters, 107, 148-163, 1991.

Green, D. H., and H. F. Wang, Fluid pressure response to undrained compression in saturated sedimentary rock, Geophysics, 51, 948-956, 1986.

Rice, J. R., and M. P. Cleary, Some basic stress diffusion solutions for fluid-saturated porous media with compressible constituents, Rev. Geophys. and Space Phys., 14, 227-241, 1976.

Roeloffs, E. A., H. F. Wang, L. S. Cheung, and B. C. Haimson, Monotonic and cyclic pores pressure loading of sawcut sandstone, Proc. 20th U. S. Symposium on Rock Mechanics, pp. 179-188, Austin TX, June 4-6, 1979.

Trimmer, D., Laboratory measurements of ultralow permeability of geologic materials, Rev. Sci. Instrum. 53, 1246-1254, 1982.

Walsh, J. B., and M. A. Grosenbaugh, A new model for analyzing the effect of fractures on compressibility, J. Geophys. Res., 87, 3532-3536, 1979.

Warren, J. E., and P. J. Root, The behavior of naturally fractured reservoirs, Soc. Pet. Eng. J., 3, 245$255,1963$.

Watson, E. B., Diffusion in fluid-bearing and slightly-melted rocks: experimental and numerical approaches illustrated by iron transport in durite, Contrib. Mineral. Petrol., 107, 417-434, 1991.

Zoback, M. D., and J. D. Byerlee, The effect of microcrack dilatancy on the permeability of Westerly granite, J. Geophys. Res., 90, 1975.

\section{PAPERS PUBLISHED AND SUBMITTED FOR PUBLICATION}

D. H. Green and H. F. Wang, Specific storage as a poroclastic coefficient, Water Resources 



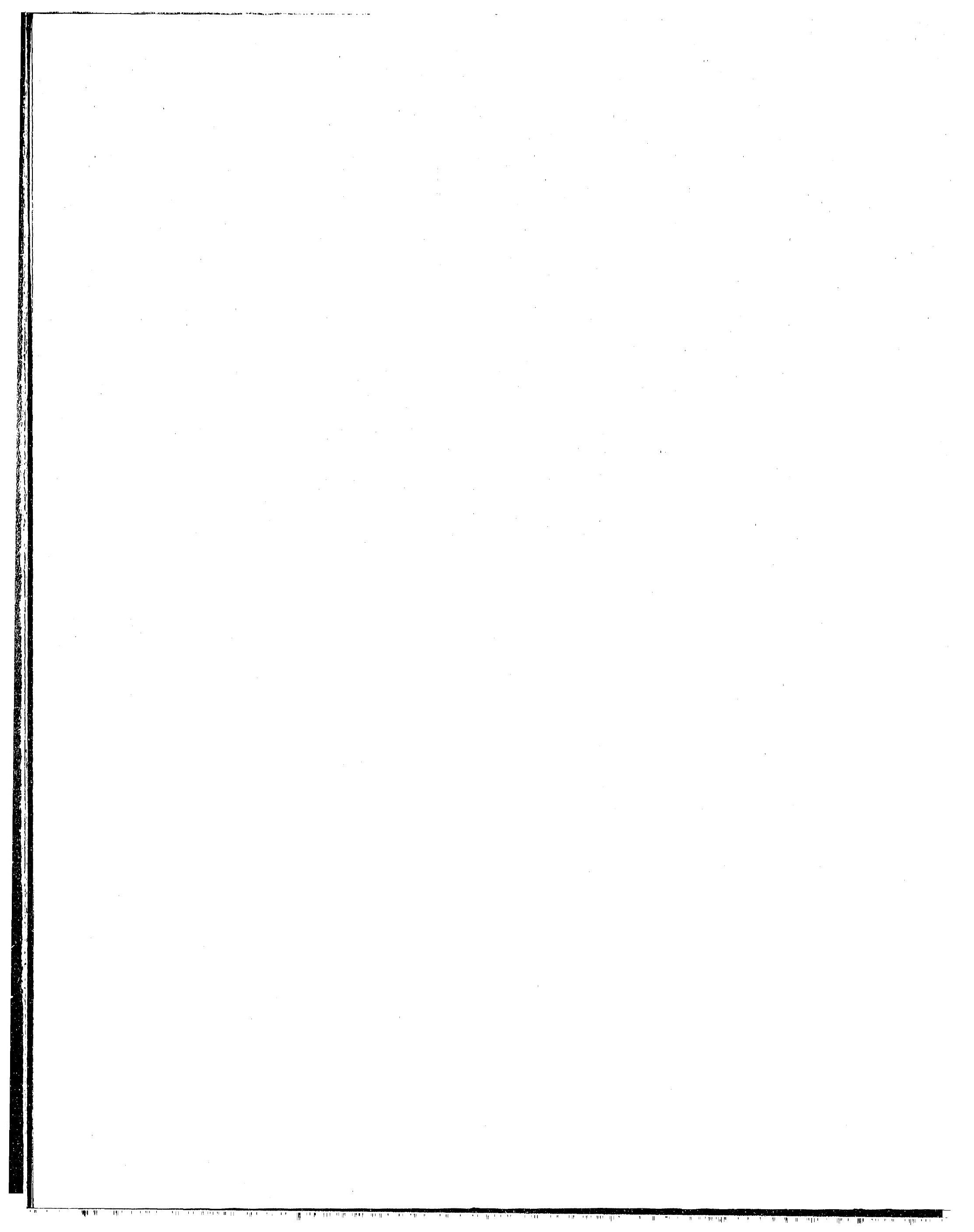

